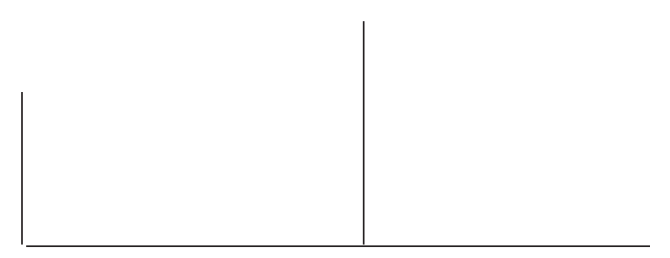

Rev. Latinoam. Psicopat. Fund., V, 1, 44-60

\title{
Os transtornos e as dificuldades da alimentação
}

\author{
Martha Hirsch Gusmão
}

\begin{abstract}
Este texto trata das recentes iniciativas de discussão da classificação dos transtornos da alimentação em bebês e na primeira infância (feeding disorders) e de seu interesse para o campo da psicanálise. A compreensão dos transtornos e dificuldades da alimentação, como uma problemática que envolve a díade mãe-criança, remete-nos aos estudos psicanalíticos das relações objetais precoces e teorias do vínculo. O elemento cuidador encontra-se integrado à etiologia dos transtornos da alimentação. Este trabalho apresenta a proposta de classificação de Irene Chatoor, com ênfase no referencial teórico psicanalítico que permite abordar a díade alimentador-alimentado. A superação da dicotomia orgânico/não-orgânico, em psiquiatria infantil, constitui importante passo no diálogo entre disciplinas afins no campo psicopatológico. O diálogo entre psiquiatria e psicanálise abre um campo de pesquisa de novas formas de intervenção e identificação de fatores de risco e situações clínicas que permitam prevenção e profilaxia.
\end{abstract}

Palavras-chave: Transtornos e dificuldades da alimentação; relação mãe-bebê (mãe-criança); psiquiatria; psicanálise; Irene Chatoor 
Saúde, beleza e formas perfeitas são temas estreitamente vinculados à alimentação, e que vêm ocupando ultimamente um lugar de maior destaque nos meios de comunicação. A relação entre estes termos nem sempre é evidente, podendo ser problemática ou até mesmo contraditória.

Freqüentemente, somos atingidos por imagens ideais de mulheres magras e esguias, na moda, que se alternam com anúncios de comida fast-food e vantagens de comer "sem parar", "incessantemente" um determinado produto apresentado como "delicioso". As crianças têm constituído um importante segmento do público-alvo, tornando-se simultaneamente objeto de preocupação e mercado importante, cujo consumo é caracterizado prioritariamente pela oralidade. O tema dos problemas relacionados com alimentação, como anorexia, bulimia, compulsões alimentares e obesidade, também vem sendo abordado pela mídia de modo cada vez mais freqüente.

Do ponto de vista de uma discussão psicopatológica trata-se de uma questão interessante e complexa. A sociedade sofre mudanças rápidas e progressivas em uma época de marcada influência mercadológica das tecnociências na vida cotidiana. Os hábitos se modificam e os rituais se desfazem, os ideais de imagem corporal são organizados e massificados, a oferta de alimentos exacerba-se com incrementos calóricos, o exercício e 


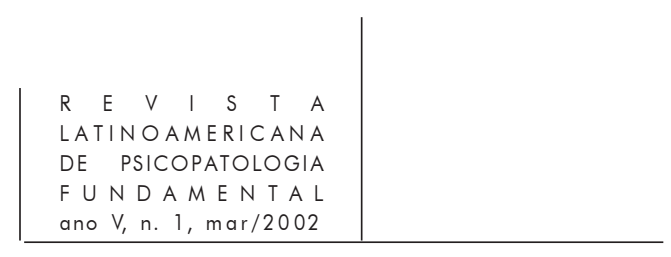

gasto calórico da vida cotidiana reduz-se ao mínimo; em suma, as mudanças da modernidade parecem, também, cristalizar-se no engendramento e/ou percepção de novas formas de adoecer, como os transtornos alimentares.

Do mesmo modo com que cresce a preocupação com a estética corporal, aumenta a prevalência da obesidade no mundo. Nos Estados Unidos este problema já atingiu um caráter de epidemia: atualmente $40 \%$ de sua população é tecnicamente qualificada como obesa (Nunes; Appolinário; Abuchaim; Coutinho, 1998).

Recentemente, algumas iniciativas de investigação em psiquiatria clínica vêm se ocupando da questão em nível nosológico e classificatório. Até a terceira edição do Manual Diagnóstico e Estatístico dos Distúrbios Mentais (DSM-III, 1980) não havia um tópico relativo a transtornos relacionados à alimentação em crianças. Já na sua quarta edição (DSM-IV, 1994) foi apresentada uma diferenciação na classificação dos transtornos alimentares (Eating disorders). Acrescentou-se, como nova categoria diagnóstica, o "Transtorno da alimentação em bebês ou na primeira infância" (Feeding disorder of infancy or early childhood). Irene Chatoor ${ }^{1}$ propôs um adendo a este tópico, apresentando uma classificação de quatro diferentes transtornos da alimentação associados a problemas de crescimento e desenvolvimento.

Observamos que o termo feeding disorder é geralmente utilizado com o intuito de sublinhar a natureza dual ou diádica dos problemas alimentares que acometem bebês e crianças pequenas. ${ }^{2}$ Em português não existe um verbo correlato a "feed". Em inglês eat significa comer, e feed significa alimentar uma criança ou um animal; dar de comer a alguém incapaz de alimentar-se por conta própria. Enquanto os transtornos alimentares (eating disorders) são perturbações no ato de comer, os transtornos da alimentação (feeding disorders) são perturbações no ato de dar de comer. Considerando-se que nos primeiros anos de vida as crianças passam por um processo de extrema dependência em relação aos seus "cuidadores" no que diz respeito à alimentação até que atinjam autonomia suficiente e prescindam do auxílio de terceiros, as dificuldades e os problemas que podem surgir no âmbito da alimentação, neste período, necessariamente envolvem a díade alimentadoralimentado. O elemento cuidador (geralmente a mãe) encontra-se, portanto, integrado à etiologia dos transtornos da alimentação.

1. Chatoor é psiquiatra, professora de psiquiatria e ciências comportamentais da Escola de Medicina da Universidade George Washington e diretora da Psiquiatria Infantil do Children's Hospital National Medical Center, em Washington. Participou como especialista da força-tarefa do DSM-IV (Manual Diagnóstico e Estatístico dos Distúrbios Mentais) e de outra iniciativa responsável pela classificação 0-3; em ambas ela é uma das principais responsáveis pelo tema dos transtornos da alimentação na infância.

2. Optamos pela tradução "transtornos da alimentação" para feeding disorders, a fim de distinguilos dos transtornos alimentares (eating disorders). 


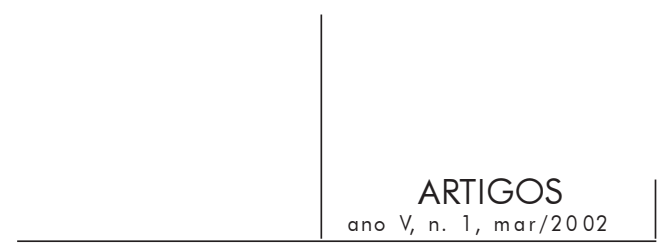

Para compreendermos tanto os motivos da inclusão da nova categoria diagnóstica no DSM-IV quanto as razões que levaram Irene Chatoor a propor uma classificação mais detalhada dos transtornos da alimentação, torna-se necessária uma digressão a respeito de um tema que tem estreita relação com a problemática abordada: trata-se do "déficit de crescimento" (failure to thrive). Este déficit é definido por um atraso no crescimento físico, acompanhado freqüentemente de um retardo no desenvolvimento social e motor. Também foi utilizado na literatura, além dos transtornos da alimentação (feeding disorders), como rótulo diagnóstico. $\mathrm{Na}$ verdade trata-se de um problema corriqueiro no consultório do pediatra, afligindo médicos e mães mesmo quando é afastado um diagnóstico clínico específico (infecções, neoplasias, etc.), pois apresenta-se como um desafio às terapêuticas usuais. Esta categoria sindrômica, emergente nas décadas de 1960 e 1970, suscita uma reflexão sobre a alimentação e o que denominamos no campo da psicanálise de relações objetais precoces. Lembremos que a alimentação é um dos cuidados maternos primordiais. É pelo contato boca-seio (ou substitutos) que o bebê organiza suas experiências sensoriais (FREUD, 1905). Na metapsicologia freudiana estas experiências corporais primitivas (dentro-fora/comer-cuspir) são simultaneamente vivências psíquicas organizadoras, capazes de traduzir de modo fantasmático relações e questões psíquicas determinantes na gênese subjetiva e no desenvolvimento individual. Nesta perspectiva podemos dizer que o conhecimento e o afeto começam pela boca. Na verdade, aquilo que entra pela boca funciona como apoio para experiências psíquicas originárias, aonde o nível cognitivo e afetivo ainda não se diferenciam.

Já em 1908, Chapin (citado por CHATOOR, 1997a) observara que o déficit de crescimento e desenvolvimento estaria, em determinados casos, associado à miséria e desnutrição, ou ao cuidado institucional precário. A partir deste tipo de inferência, criou-se uma diferenciação entre o déficit de crescimento orgânico e não-orgânico. Desde então, várias pesquisas procuraram descrever os diferentes fatores causadores do déficit, baseando-se nesta dicotomia. Na década de 1940, René Spitz (1945) chamou de "hospitalismo" uma síndrome específica observada em crianças criadas em instituições, que apresentavam sérios retardos de crescimento e desenvolvimento. Na mesma época, Spitz (1946) também associou o déficit de crescimento de origem não-orgânica em bebês ao fato de terem sido afastados de suas mães de modo abrupto, entre os seis e doze meses de idade.

Nas décadas de 1960 e 1970 foram realizados diversos estudos a respeito do déficit de crescimento não-orgânico, compreendido então como reflexo da falta em prover ou relativa ausência de carinho e cuidados maternais adequados (CHATOOR, 1997b). Do mesmo modo, vários trabalhos foram desenvolvidos acerca do déficit de crescimento de origem orgânica, buscando descrever um conjunto de doenças que poderiam provocar atrasos no crescimento e desenvolvimento. Na década de 1980 


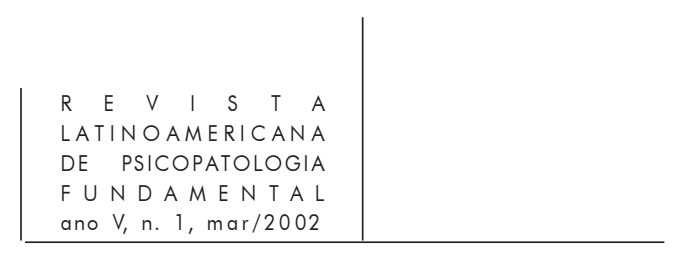

(CHATOOR, 1997b) foi sugerida uma terceira categoria, que combina fatores orgânicos e não-orgânicos na etiologia de certos casos de distúrbios de crescimento.

Apesar de alguns autores utilizarem os termos "transtornos da alimentação" (feeding disorders) e "déficit de crescimento" (failure to thrive) indiscriminadamente, verificou-se que nem todas as crianças que apresentam transtornos da alimentação têm problemas de crescimento e desenvolvimento, assim como também o déficit de crescimento nem sempre está associado a transtornos da alimentação. Os dois termos, portanto, não são equivalentes. Segundo Irene Chatoor (1997a), a nova categoria diagnóstica do DSM-IV foi o primeiro passo em relação à distinção entre o transtorno da alimentação e o déficit de crescimento, entretanto, ela critica a definição proposta considerando-a muito geral, não levando em conta a heterogeneidade de transtornos da alimentação associados a problemas de crescimento e suas implicações para o tratamento.

Talvez não esteja ainda muito claro a inovação de perspectiva que Irene Chatoor propõe e sua repercussão psicopatológica. Observamos que a classificação do transtorno da alimentação em bebês, ou na primeira infância, do DSM-IV, exclui todos os casos em que ocorrem problemas na alimentação associados a problemas orgânicos. (Estes distúrbios são classificados separadamente a partir do diagnóstico pediátrico no eixo III do DSM-IV, relativo às doenças orgânicas). Ou seja, o DSM-IV mantém a dicotomia entre o déficit de crescimento de origem orgânica ou nãoorgânica, enquadrando no tópico "transtorno da alimentação" apenas os casos em que o déficit de crescimento é exclusivamente de origem não-orgânica.

Chatoor, por sua vez, discorda radicalmente da dicotomia orgânico-não-orgânico na diferenciação do déficit de crescimento. Já em 1984/85 propôs uma classificação dos transtornos da alimentação associados ao déficit de crescimento, incorporandolhe uma etiologia multifatorial do déficit. Naquela classificação ela inclui uma gama de fatores orgânicos e não-orgânicos que podem tanto criar ou exacerbar quanto tornarem-se seqüelas de problemas de crescimento. É nisto que reside a originalidade de sua proposta. A autora observa que mesmo em certos casos em que se constata problemas de ordem orgânica, estes podem contribuir, mas não explicar totalmente os problemas da alimentação. Como veremos mais adiante, esta nova perspectiva inaugura todo um campo de investigação e pesquisa. Viabilizando o diálogo entre medicina e psicanálise, abre um espaço para novas formas de compreensão e, conseqüentemente, de intervenção no tratamento das dificuldades e dos transtornos relativos à alimentação em crianças. A concepção de Chatoor tende a um modelo etiológico multicausal, que integra organismo, cuidadores, meio ambiente e até estímulos iatrogênicos, em complexa inter-relação.

Na classificação de Irene Chatoor são diferenciados dois tipos de transtornos da alimentação. O primeiro, que compreende três diferentes subtipos de transtornos, é caracterizado como desenvolvimental. Nestes casos, os sintomas se expressam em 
um indivíduo (o bebê), porém refletem problemas na relação e o progresso no relacionamento mãe-bebê não segue o curso do desenvolvimento normal. O segundo tipo, denominado pós-traumático, pode ocorrer em diferentes idades e estágios de desenvolvimento.

Quanto ao primeiro tipo, baseando-se nos estágios do desenvolvimento infantil de Greenspan e Lourie (1981) e no conceito de separação-individuação de Margaret Mahler (1993), Chatoor distingue três estágios do desenvolvimento da alimentação (stages of feeding development) nos quais são identificados os comportamentos adaptativos e não-adaptativos, tanto nas crianças quanto nas mães. A diferenciação destes estágios, nomeadamente "homeostase", "apego" e "separação", serve de base para a classificação dos três diferentes subtipos. Deste modo, dependendo do estágio do desenvolvimento da criança em que o transtorno se inicia, ele será classificado como transtorno da alimentação na homeostase (Feeding disorder of homeostasis), transtorno da alimentação no apego (Feeding disorder of attachment) ou transtorno da alimentação na separação (Feeding disorder of separation).

É interessante observar que, de acordo com a concepção de Margaret Mahler sobre o desenvolvimento infantil normal, o bebê atravessa inicialmente uma fase "autista normal", na qual o objetivo principal é a aquisição do equilíbrio homeostático através de mecanismos somatopsíquicos e fisiológicos. A seguir, na fase "simbiótica normal", o bebê funciona como se ele e sua mãe fossem uma unidade dual onipotente dentro de uma fronteira comum. Estas duas fases iniciais são consideradas prérequisitos indispensáveis para o estabelecimento do processo normal de separaçãoindividuação, que compreende quatro subfases e culmina no momento em que a criança já percebe a mãe como uma pessoa separada no mundo externo, e também fazendo parte do seu mundo de representação interna, passando a se interessar progressivamente por jogos e buscando o contato com pares e outros adultos.

$\mathrm{O}$ importante de todo este processo, e que nos interessa particularmente em relação à problemática dos transtornos da alimentação, é a ênfase que Margaret Mahler confere ao papel da mãe nas diferentes etapas do desenvolvimento do bebê e da criança pequena. $\mathrm{O}$ desenvolvimento normal implica em dificuldades que, para serem ultrapassadas, exigem um determinado posicionamento materno. Segundo Mahler, a disponibilidade da mãe para acompanhar o desenvolvimento da criança, adaptandose às suas necessidades e reconhecendo suas dificuldades e conflitos, é crucial para que ela possa adquirir sua individualidade.

Entre os psicanalistas que estudaram a relação objetal precoce (que envolve a díade), Winnicott - considerado um "ambientalista" porque se interessou profundamente pelas conexões entre o bebê, a mãe e o meio ambiente - nos remete a duas formulações que sublinham a importância atribuída ao papel da mãe no desenvolvimento infantil: trata-se dos conceitos de "preocupação materna primária" e "mãe suficientemente boa". Para este autor, desde a gravidez a mulher desenvolve 


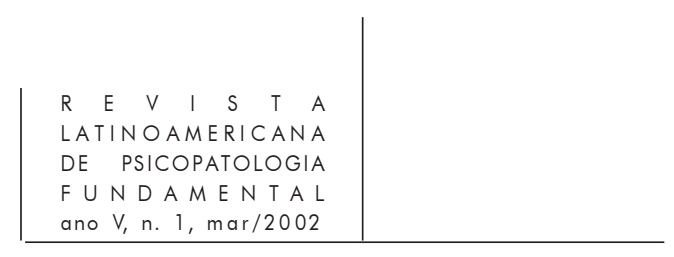

um processo de identificação com o seu bebê, sendo o ápice deste processo atingido no período perinatal, diminuindo gradativamente nas semanas e meses subseqüentes. $\mathrm{O}$ estado identificatório permite que a mãe pressinta as necessidades e expectativas mais precoces do seu bebê, sabendo como protegê-lo. Quando a mãe não é suficientemente boa, um self verdadeiro não pode se tornar uma realidade e o bebê é forçado a uma falsa existência. Winnicott comenta que nestas circunstâncias o quadro clínico que se apresenta é o de "irritabilidade generalizada e de distúrbios da alimentação e outras funções que podem, contudo, desaparecer clinicamente, mas apenas para aparecer de forma severa em estágio posterior" (WINNICOTT, 1983, p. 134). Esta passagem não deixa dúvidas quanto à estreita relação entre os problemas de alimentação e a relação mãe-bebê.

A alimentação ocupa um lugar central no desenvolvimento infantil, já que é em torno dela que se organizam, desde o nascimento, os primeiros contatos entre a mãe e o bebê, assim como também se delineiam e se expressam os conflitos da díade mãebebê. Do mesmo modo que a criança progressivamente vai adquirindo uma relativa independência em relação à sua mãe, sendo desejável que suporte suas ausências, assim como também a mãe suporte distanciar-se do filho, no que concerne à alimentação é esperada uma independência gradual que tem grande importância, embora ocorra de forma sutil e despercebida.

O que Chatoor denominou de "estágios do desenvolvimento da alimentação" constitui-se numa seqüência de etapas que acompanham o processo de desenvolvimento normal. A alimentação do bebê sofre uma série de mudanças desde o nascimento até a idade em que a criança se torna capaz de se alimentar de modo autônomo. Estas mudanças nem sempre são bem aceitas (pelas crianças e mesmo pelas mães), sendo muito comum o aparecimento de dificuldades relativas à alimentação justamente nos períodos de transição (do seio - ou substitutos - ao desmame, à introdução da alimentação pastosa e à comida sólida).

$\mathrm{Na}$ classificação de Irene Chatoor $^{3}$ cada transtorno é descrito por meio de suas características principais, a idade em que se inicia, os aspectos relativos ao bebê (criança), aos pais, à relação mãe-bebê e, por fim, o diagnóstico diferencial.

Ainda em relação ao primeiro tipo (desenvolvimental), podemos observar que no transtorno da alimentação na homeostase (primeiro subtipo), as dificuldades na regulação da alimentação estão intimamente ligadas à relação mãe-bebê, mesmo quando ocorrem problemas orgânicos associados, que contribuem para os problemas da alimentação. A reciprocidade mãe-bebê empobrecida e a tensão materna durante as mamadas incrementam os problemas relativos à alimentação. Entretanto, de um modo geral, a mãe se mostra preocupada com a alimentação do seu filho, o que não

3. Ver apêndice. 


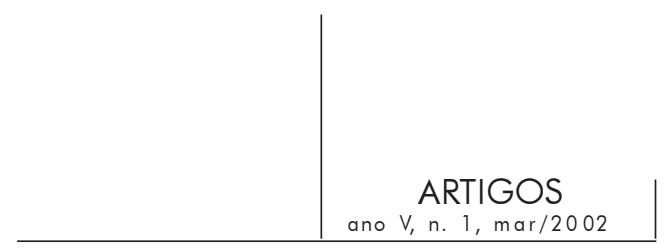

ocorre no transtorno da alimentação no apego (segundo subtipo), quando a mãe freqüentemente omite, ou até mesmo nega, qualquer problema de alimentação do bebê. Neste transtorno, as características da relação mãe-bebê - falta de engajamento mútuo e falta de prazer no relacionamento - sugerem uma patologia materna mais grave. Casos em que condições orgânicas poderiam conduzir à falta de ganho de peso no bebê ficam excluídos. Deve-se destacar que a drogadição e depressão maternas são patologias que perturbam profundamente a díade, e encontram-se relacionadas com este transtorno.

O transtorno da alimentação na separação, ou anorexia infantil (terceiro subtipo), ocorre na transição do bebê para a alimentação autônoma. A recusa de alimento gera um enorme conflito entre a mãe e o bebê. As inúmeras tentativas maternas, no sentido de levar o bebê a comer, resultam numa intensificação do conflito: a ingestão ou recusa alimentar torna-se resultado da interação de ambos, de modo que a regulação da alimentação do bebê passa a ser externa em vez de interna. Isto significa que a criança não regula mais a sua alimentação pela sensação de fome e saciedade. Os casos em que a recusa alimentar se deve a um evento traumático ficam excluídos e serão descritos a seguir.

O segundo tipo de transtornos da alimentação é denominado pós-traumático. Não apresenta nenhum subtipo, sendo diferenciado exclusivamente quanto à idade em que ele se manifesta. Em bebês e crianças pequenas é chamado de transtorno póstraumático da alimentação (posttraumatic feeding disorder); em crianças maiores transtorno alimentar pós-traumático (posttraumatic eating disorder). Este transtorno caracteriza-se por uma ruptura mais aguda na regulação da alimentação. O início da recusa parcial ou total de alimento se dá após um episódio traumático, tal como engasgo, vômito, sufocação ou procedimentos corriqueiros em ambientes de urgência ou UTI, como inserção de tubo endotraqueal, sonda nasogástrica ou enteral. Com o avanço tecnológico, estes procedimentos vêm se tornando cada vez mais freqüentes, o que justifica a importância de identificar corretamente e tratar suas conseqüências.

Estudos longitudinais mostraram a conexão entre problemas na alimentação, durante a primeira infância, e transtornos alimentares, na adolescência. Associou-se sintomas gastrointestinais e picky eating ${ }^{4}$ na infância com comportamento anoréxico na adolescência, assim como os comportamentos problemáticos durante as refeições, e pica ${ }^{5}$ na infância, foram correlacionados com bulimia nervosa na adolescência (CHATOOR, 1997b). A articulação entre infância (feeding disorders) e adolescência

4. Trata-se de uma forma subclínica da anorexia infantil (ou transtorno da alimentação na separação). Picky significa altamente fastidioso, meticuloso, de gosto delicado, tedioso, enfadonho.

5. Transtorno que se caracteriza pela persistente ingestão de substâncias não-nutrientes (tinta, papel, tecido, excremento animal, areia, pedra, sujeira). 


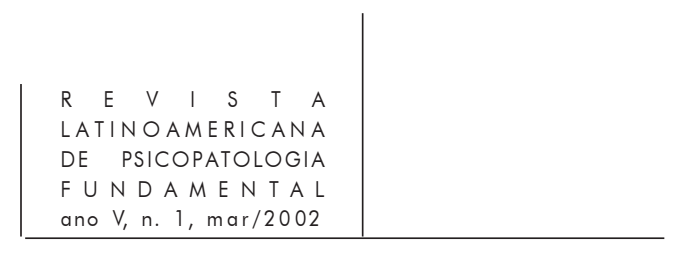

(eating disorders) pode permitir um salto na compreensão dinâmica de processos que eram somente visíveis e melhor conhecidos mais tardiamente.

A classificação de Chatoor é de extrema importância para o campo da psicanálise. Ao relativizar a dicotomia orgânico-não-orgânico em função da proposta de uma etiologia multifatorial do déficit, ela abre todo um campo de investigação dos aspectos psíquicos envolvidos nos transtornos da alimentação, inclusive em certos casos em que são observados problemas de ordem orgânica. Ao mesmo tempo, quando atribui especial ênfase à díade alimentador-alimentado, distinguindo, portanto, os transtornos da alimentação (feeding disorders) dos demais transtornos alimentares (eating disorders), reserva um lugar de destaque à figura da mãe (ou cuidador), cuja dificuldade em responder adequadamente às diferentes etapas do desenvolvimento do bebê e da criança pequena pode se constituir num fator desencadeante, causal ou mantenedor dos transtornos da alimentação. Em outros termos, a mãe cumpre um importante papel tanto em relação ao diagnóstico quanto ao tratamento e prognóstico.

A noção de alimentação (feeding) envolvendo a díade traz à tona problemas com os quais diversos teóricos da psicanálise já se ocupavam, tais como: identificação, amor primário, relações objetais precoces, simbiose, separação. Acreditamos que, além dos autores tomados como referencial pelo grupo de Irene Chatoor, por exemplo, Greenspan e Lourie, escola do Attachment e psicanalistas como Margaret Mahler, as contribuições de outros teóricos da psicanálise, tais como Winnicott, Klein, Balint, Anzieu, Stern, podem lançar mais uma luz à problemática estudada. Torna-se imperioso empreender uma releitura crítica da literatura psicanalítica de relação objetal precoce na tradição da psicanálise com crianças, ${ }^{6}$ visando uma análise sistemática de aspectos relativos à alimentação (feeding).

É importante ainda atentar para aspectos epidemiológicos que indicam a relevância do tema na atualidade. Estima-se que cerca de 35\% dos bebês e crianças pequenas apresentam problemas ou dificuldades na alimentação (feeding problems/ feeding difficulties), que vão desde a ingestão insuficiente ou excessiva de alimento, restrições em relação às preferências alimentares, atraso na passagem para a alimentação autônoma, comportamentos objetáveis às refeições, até hábitos alimentares bizarros (CНАTOOR, 1997b). Este percentual engloba, portanto, todos os casos em que são observados desde dificuldades relativas à alimentação até os transtornos da alimentação propriamente ditos. Pesquisas mostraram que casos graves de recusa alimentar ou vômitos, associados a ganho de peso insatisfatório, ocorrem em cerca de $1 \%$ a $2 \%$ dos bebês de até um ano de idade (СнатооR, 1997a).

6. Cf. minha tese sendo desenvolvida no âmbito de uma linha de pesquisa de psicanálise clínica no hospital (Instituto Fernandes Figueira-FIOCRUZ, RJ) centrada na revisão do problema da relação objetal precoce. 


\section{ARTIGOS}

ano $V$, n. 1, mar/2002

Embora ainda não existam estudos de prevalência sobre os diferentes transtornos da alimentação, definidos por Irene Chatoor, evidencia-se um aumento progressivo na incidência de transtornos da alimentação pós-traumáticos. Isto se explica pelo número crescente de crianças que sobrevivem a complicações clínicas graves. O progresso tecnológico no campo da neonatologia tem resultado numa considerável redução da taxa de mortalidade neonatal. Os chamados "filhos das máquinas", isto é, prematuros e recém-nascidos portadores de patologias graves, sobrevivem hoje graças à atenção cada vez mais intensiva e sofisticada decorrente da alta tecnologia utilizada em medicina (VIzziello; ZoRzi; BotTos, 1993). Os recémnascidos de baixo peso sobrevivem cada vez mais à custa de longas temporadas em UTIs, sofrendo múltiplas intervenções e com sua relação diádica perturbada. A repercussão psíquica desta experiência oral traumática constitui uma área de interesse para os estudos psicanalíticos da relação mãe-bêbe, assim como para estudos sobre o vínculo (attachment).

\section{Conclusão}

Sublinhamos a importância da iniciativa de Irene Chatoor, no sentido de uma classificação detalhada dos transtornos da alimentação, entendidos como uma problemática que envolve a díade mãe-bebê ou mãe-criança, assim como a necessidade de se identificar, diagnosticar e tratar precocemente tanto estes transtornos como, também, os casos de dificuldades relativas à alimentação ou formas subclínicas de transtornos da alimentação, como, por exemplo, os casos de picky-eating que, mesmo não se enquadrando na classificação proposta, requerem atenção especializada.

Destacamos, ainda, a importância de retomar a literatura sobre as relações objetais precoces a partir de um problema, portanto, sem a preocupação em distinguir escolas teórico-metapsicológicas, assim como o valor do diálogo da psicanálise com a psiquiatria (da infância e da adolescência), no sentido de demarcar um campo psicopatológico comum. Consideramos a classificação proposta por Irene Chatoor de extrema relevância na identificação de fatores de risco e situações clínicas que permitam prevenção e profilaxia. 
Apêndice ${ }^{7}$ :

Transtorno da Alimentação na Homeostase (Feeding Disorder of Homeostasis)

Características principais: dificuldade em estabelecer mamadas (feedings) regulares e calmas, ingestão inadequada de alimento e dificuldade de regulação da alimentação que, nos primeiros meses de vida, está intimamente ligada à relação mãe-bebê. Características do bebê e dos pais contribuem para estas dificuldades regulatórias.

Bebê (Infant) Início das dificuldades de alimentação: 0 a 3 meses de idade.

A alimentação tem um padrão irregular (quanto à quantidade ingerida e à duração das mamadas) e a ingestão de alimento é, de um modo geral, deficiente.

Irritabilidade, fatigabilidade rápida ou sonolência excessiva.

Déficit de crescimento e desenvolvimento (failure to thrive) devido à ausência de ganho de peso.

Pais (Parents)

Ansiedade parental, depressão, doença psiquiátrica ou estressores psicossociais são responsáveis pela inabilidade materna em facilitar as mamadas (feedings), tornando-as calmas e bem-sucedidas. Incapacidade de ler ou interpretar os sinais (as "dicas") do bebê.

Relação Mãe-bebê

Tensão materna durante as mamadas (feedings).

(Mother-Infant

Reciprocidade mãe-bebê empobrecida.

Relationship)

Diagnóstico

Diferencial
O bebê pode apresentar problemas orgânicos associados que podem contribuir para os problemas da alimentação, mas não explicálos totalmente. (Pré-termo, imaturidade funcional, doença cardíaca ou pulmonar, anormalidades funcionais ou estruturais da orofaringe ou trato intestinal (por exemplo, fenda palatina, refluxo gastroesofageano, atresia esofageana).

7. Este apêndice consiste de quatro tabelas, elaboradas a partir das tabelas apresentadas por Irene Chatoor (1997b). 


\section{ARTIGOS}

ano $V$, n. 1, mar/2002

Transtorno da Alimentação no Apego (Feeding Disorder of Attachment)

Característica principal: falta de engajamento entre mãe e bebê.

\begin{tabular}{|c|c|}
\hline \multirow[t]{3}{*}{ Bebê (Infant) } & Início do déficit de crescimento: entre 2 e 8 meses de idade. \\
\hline & Falta de interação social adequada à idade. \\
\hline & Atraso no desenvolvimento cognitivo e motor. \\
\hline \multirow[t]{2}{*}{ Pais (Parents) } & $\begin{array}{l}\text { Depressão aguda ou crônica, ou distúrbio de personalidade, abuso } \\
\text { de drogas ou álcool, e elevado estresse psicossocial. } \\
\text { Falta de cuidado afetuoso. }\end{array}$ \\
\hline & $\begin{array}{l}\text { Alimentação (do bebê) irregular: alimentações podem ser } \\
\text { esquecidas; mamadeiras podem ser oferecidas ao bebê para que } \\
\text { ele se alimente de modo independente. A mãe freqüentemente nega } \\
\text { qualquer problema de alimentação do bebê, que pode se tornar alvo } \\
\text { da atenção dos profissionais devido ao déficit de crescimento ou } \\
\text { outros problemas de saúde. }\end{array}$ \\
\hline $\begin{array}{l}\text { Relação Mãe-bebê } \\
\text { (Mother-Infant } \\
\text { Relationship) }\end{array}$ & $\begin{array}{l}\text { Falta de engajamento mútuo. } \\
\text { Falta de prazer no relacionamento entre mãe e bebê. }\end{array}$ \\
\hline $\begin{array}{l}\text { Diagnóstico } \\
\text { Diferencial }\end{array}$ & $\begin{array}{l}\text { Deve-se diferenciar este transtorno de condições orgânicas que } \\
\text { podem conduzir à falta de ganho de peso no bebê. Mas } \\
\text { normalmente nestes casos mãe e bebê apresentam um bom } \\
\text { engajamento mútuo. }\end{array}$ \\
\hline
\end{tabular}




\section{Anorexia Infantil- Transtorno da Alimentação na Separação (Feeding Disorder of Separation)}

Características principais: recusa de alimento do bebê; intenso conflito na relação mãe-bebê em torno de questões relativas à autonomia, dependência e controle.

\begin{tabular}{l|l} 
Bebê (Infant) & $\begin{array}{l}\text { Início da recusa de alimento: entre } 6 \text { meses e } 3 \text { anos, (na transição } \\
\text { do bebê para alimentação autônoma e independente). }\end{array}$
\end{tabular}

Recusa de alimento variando em diferentes refeições e com diferentes cuidadores.

Ingestão de alimento inadequada.

Déficit de crescimento e desenvolvimento.

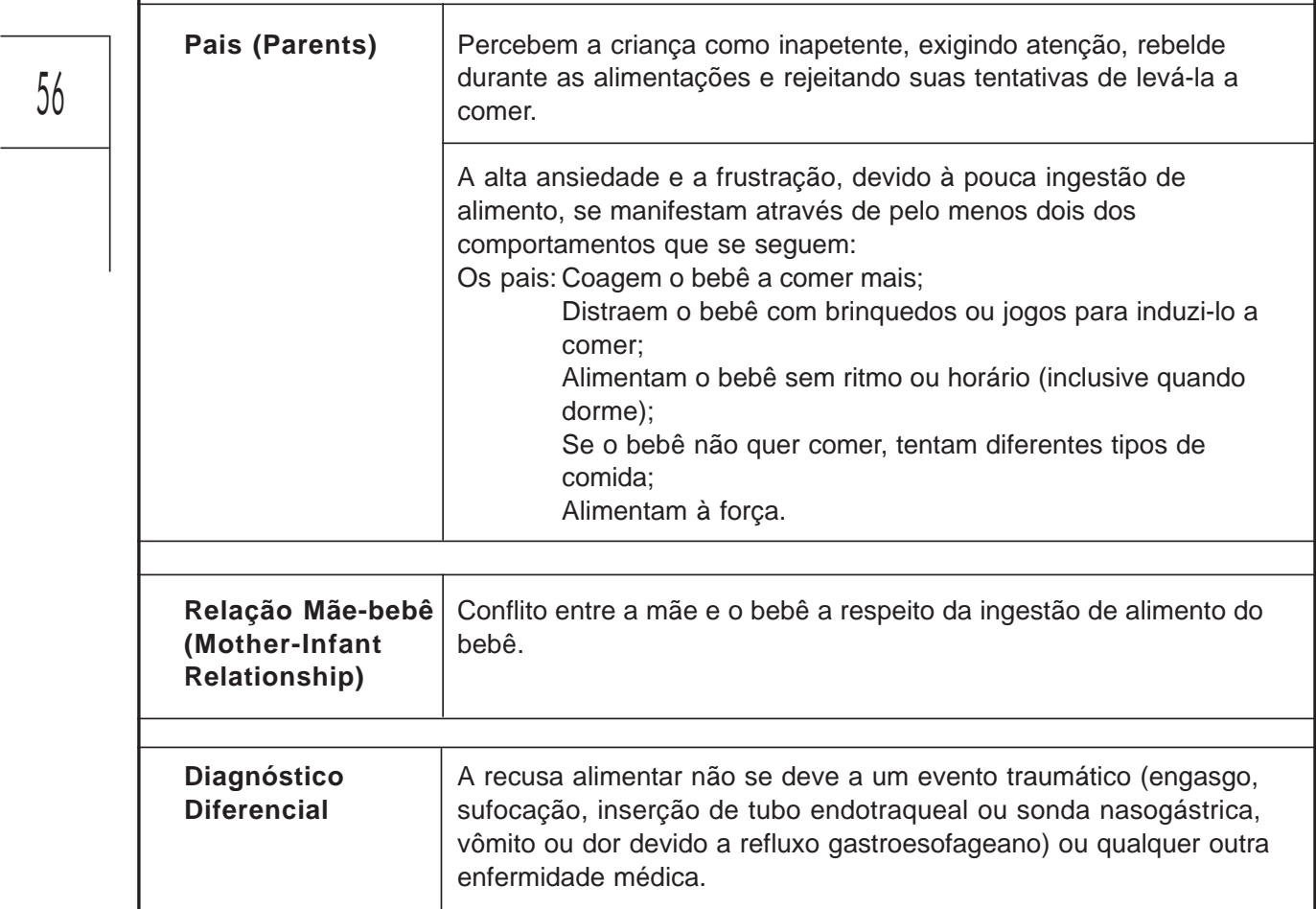




\section{ARTIGOS}

ano $V$, n. 1, mar/2002

\section{Transtorno da Alimentação Pós-traumático}

(Posttraumatic Feeding Disorder)

Características principais: recusa total de alimento do bebê ou recusa em comer ou engolir leite ou comida (textured food); boa reciprocidade mãe-bebê em outras circunstâncias.

\begin{tabular}{|c|c|}
\hline \multirow{3}{*}{$\begin{array}{l}\text { Recusa de } \\
\text { Alimento pelo } \\
\text { bebê (infant) }\end{array}$} & Início da recusa de alimento é súbito. \\
\hline & $\begin{array}{l}\text { Recusa total: bebê parece associar alimentação com dor ou } \\
\text { estresse; apresenta medo antecipatório, por exemplo, choro, } \\
\text { engasgo e vômito na presença de mamadeira ou cadeira de comer, } \\
\text { ou quando alimentado à força. }\end{array}$ \\
\hline & $\begin{array}{l}\text { Recusa parcial: bebê parece associar certos tipos de alimento (leite } \\
\text { ou comida) com dor, por exemplo, recusa mamadeira, mas aceita } \\
\text { comida de colher; toma mamadeira sonolento, mas não toma se } \\
\text { estiver acordado; retém comida na boca e depois cospe, chora, } \\
\text { engasga e sufoca quando alimento à força. }\end{array}$ \\
\hline Pais (Parents) & $\begin{array}{l}\text { A ansiedade e frustração, devidos à recusa de alimentação pela } \\
\text { criança, se manifestam através dos seguintes comportamentos: } \\
\text { Engambelam o bebê com brinquedos durante as mamadas } \\
\text { (refeições); } \\
\text { Tentam alimentá-lo dia e noite; } \\
\text { Experimentam diferentes tipos de comida, sem sucesso; } \\
\text { Tentam alimentar à força (com isso intensificam os } \\
\text { sintomas de ansiedade antecipatória e recusa alimentar). }\end{array}$ \\
\hline $\begin{array}{l}\text { Relação Mãe-bebê } \\
\text { (Mother-Infant } \\
\text { Relationship) }\end{array}$ & $\begin{array}{l}\text { Ansiedade e tensão em antecipação e durante a mamada (refeição) } \\
\text { Interações prazerosas quando brincam ou jogam. }\end{array}$ \\
\hline $\begin{array}{l}\text { Diagnóstico } \\
\text { Diferencial }\end{array}$ & $\begin{array}{l}\text { Deve ser diferenciado do transtorno da alimentação na separação } \\
\text { (anorexia infantil) e do "picky eating" (altamente fastidioso, } \\
\text { meticuloso, de gosto delicado, tedioso, enfadonho). }\end{array}$ \\
\hline
\end{tabular}




\section{Referências}

BARBER, J.K. Bulimia nervosa. In: WiEnER, J.M. (ed.). Textbook of child and adolescent psychiatry. 2a ed. Washington DC: American Psychiatric Press, 1997. p. 563-72.

Benort, D. Phenomenology and treatment of failure to thrive. In: Woolston, J. (ed.). Child and Adolescent Psychiatric Clinics of North America. New York: Plenum, 1993. v. 2, p. 61-73.

ChAPIN, H.D. A plan of dealing with atrophic infants and children. Archives of Pediatrics, n. 25, p. 491-6, 1908 .

CHATOOR, I. Feeding and eating disorders of infancy and early childhood. In: WIENER, J.M. (ed.). Textbook of child and adolescent psychiatry. $2^{\underline{a}}$ ed. Washington DC: American Psychiatric Press, 1997a. p. 527-42.

Feeding and other disorders of infancy or early childhood. Psychiatry, Philadelphia, v. 1, p. 683-701, 1997b.

et al. Attachment and feeding problems: a reexamination of nonorganic failure to thrive and attachment insecurity. Journal of the American Academy of Child \& Adolescent Psychiatry, v. 37, n. 11, p. 1217-24, 1998.

Снатоов, I. et al. Diagnosing infantile anorexia: the observation of mother-infant interactions. Journal of the American Academy of Child \& Adolescent Psychiatry, v. 37, n. 9, p. 959-67, 1998.

58 CHAтоOR, I. et al. Maternal characteristics and toddler temperament in infantile anorexia. Journal of the American Academy of Child \& Adolescent Psychiatry, v. 39, n. 6, p. 743-51, 2000.

Freud, S. Zur Einführung des Narzissmus, Das Ich und das Es und andere metapsychologische Schriften. Frankfurt: Fischer Taschenbuch, 1914. p.19-42.

Triebe und Triebschiksale, Das Ich und das Es und andere metapsychologische Schriften. Frankfurt: Fischer Taschenbuch, 1915. p. 43-60.

(1906). My views on the part played by sexuality in the aetiology of the neurosis. In: Richards, A. (ed.). On Psychopathology. London: Penguin Books, 1979. v. 10, p. 67-82.

Greenberg, J.R. e Mitchell, S.A. Relações objetais na teoria psicanalítica. Trad. Emília Diehl. Porto Alegre: Artes Médicas, 1994.

GreensPan, S.I. \& Lourie, R.S. Developmental structuralist approach of adaptive and pathologic personality organizations: infancy and early childhood. Am. J. Psychiatry, n. 138, p. $725-35,1981$.

Herzog, D.B. \& Beresin, E.V.. Anorexia nervosa. In: Wiener, J.M. (ed.). Textbook of child and adolescent psychiatry. 2를 ed. Washington DC: American Psychiatric Press, 1997. p. 543-62.

MAHLER, M.S. et al. O nascimento psicológico da criança. Porto Alegre: Artes Médicas, 1993.

Modell, A.H. Amor objetal e realidade. Trad. Marina B. Machado. Rio de Janeiro: Imago, 1973.

Nunes, M.A; et al. Transtornos alimentares e obesidade. Porto Alegre: Artes Médicas, 1998. 


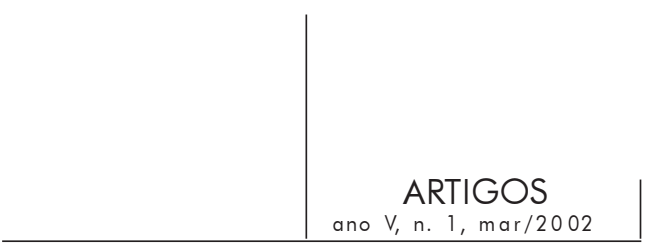

Schilder, P. (1935). A imagem do corpo. As energias construtivas da psique. Trad. Rosanne Wertman. 2 ${ }^{\underline{a}}$ ed. São Paulo: Martins Fontes, 1994.

SpItz, R.A. Hospitalism: an inquiry into the psychiatric conditions of early childhood. Psychoanal. Study Child, n. 1, p. 53-74, 1945.

Anaclitic depression: an inquiry into the psychiatric conditions of early

childhood. Psychoanal. Study Child, n. 2, p. 313-42, 1946.

O primeiro ano de vida. São Paulo: Martins Fontes, 1998.

VAN-DEN-BERG, J.H. (1962). El cuerpo humano y la significación del movimiento humano - estudio fenomenológico. In: Ruitenbeek, H.M. (ed.). Psicoanálisis y filosofía existencial. Madrid: Editorial Gredos, 1972. v. 1, p. 122-61.

Vizziello, G.F. et al. (ed.). Los hijos de las máquinas. La vida de los niños internados en terapias intensivas neonatales. Buenos Aires: Nueva Visión, 1993.

Winnicott, D.W. A influência do desenvolvimento emocional sobre os problemas de alimentação. In: Pensando sobre crianças. Porto Alegre: Artes Médicas, 1967. p. 59-60. A criança e o seu mundo. 6a ed. Rio de Janeiro: LTC, 1982.

O ambiente e os processos de maturação. Porto Alegre: Artes Médicas, 1983.

Natureza humana. Rio de Janeiro: Imago, 1990.

Pensando sobre crianças. Porto Alegre: Artes Médicas, 1997.

Woolston, J.L. Diagnostic classification: the current chalenge in failure to thrive. In: Drotar, D. (ed.). New directions in failure to thrive: research and clinical practice. New York: Plenun, 1985. p. 225-33.

Obesity of infancy and childhood. In: WIENER, J.M. (ed.). Textbook of child and adolescent psychiatry. 2ª ed. Washington DC: American Psychiatric Press, 1997. p. 573-80.

\section{Resumos}

Este texto trata de las recientes iniciativas de discusión de la clasificación de los disturbios de alimentación (feeding disorders) de bebés en la primera infancia así como del interés que esto tiene para el campo psicoanalítico. La comprensión de los disturbios y dificultades de la alimentación como una problemática que implica la pareja madre-niño nos remite a los estudios psicoanalíticos de las relaciones de objeto precoces y a las teorías del vínculo. El elemento que nutre y cuida (sea la madre o un substituto) es parte integrante de la etiología de los disturbios de la alimentación. El trabajo presenta la propuesta de clasificación de Irene Chatoor, haciendo énfasis en la base teórica que permite abordar, desde el punto de vista psicoanalítico, la pareja alimentador-alimentado. La superación de la dicotomía orgánico/no orgánico en psiquiatría infantil constituye un importante paso para alcanzar la armonía entre las disciplinas que trabajan con el campo psicopatológico. El diálogo entre psiquiatría y psicoanálisis abre un vasto campo de investigación sobre nuevas formas de intervención, de identificación de factores de riesgo y de situaciones clínicas que ofrecen oportunidad de prevención y profilaxis. 


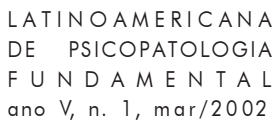

Palabras clave: Disturbios y dificultades de la alimentación; relación madre-bebé (madre-niño); psiquiatría; psicoanálisis; Irene Chatoor

Cet article vise à étudier les nouveaux développements de la classification des troubles alimentaires des nourrissons et des enfants dans la première enfance (feeding disorders) et introduit ce sujet dans le champ de la psychanalyse. La compréhension des troubles et difficultées alimentaires comme une problématique qui enveloppe la dyade mère-enfant nous renvoie à l'importance des études psychanalytiques sur les rélations objectales précoces et sur les théories du lien. L'élement soignant (soit la mère ou une substitute) est intégré à l'étiologie des troubles alimentaires. Ce travail présente comme proposition la classification de Irene Chatoor et il aborde la dyade nourrice-nourrisson par le biais psychanalytique. Le dépassement de la dichotomie organique-non organique dans la psychiatrie infantile a réussi a établir un dialogue entre les disciplines qui ont rapport avec la psychopathologie. Le dialogue entre la psychiatrie et la psychanalyse ouvre un champ de recherche sur les différentes formes d'intervention et d'identification des facteurs de risque et des situations qui permettent leur prévention et prophylaxie.

Mots clés: Troubles et difficultées alimentaires, relation mère-bébé (mère-enfant), psychiatrie, psychanalyse, Irene Chatoor

This paper reviews recent discussions on the classification of feeding disorders and its psychoanalytical importance and impact. Understanding feeding disorders by focusing on the mother-infant dyad is closely related to psychoanalytical research on early object relations and attachment theories. The caregiving and feeding agent takes an active role in the etiology of feeding disorders. This paper presents Irene Chatoor's proposal of classification, stressing the theoretical psychoanalytical background involved in the clinical approach to the dyad. The overcoming of the organic-nonorganic dichotomy in child psychiatry is an important step towards dialog and collaboration among closely related disciplines in the field of psychopathology. The possibility of integration between psychoanalysis and psychiatry opens up new inroads in the field of research, including new approaches and sharper identification of risk factors and clinical challenges that could be prevented or avoided earlier and more precisely.

Key words: Feeding disorders and feeding difficulties, mother-infant (mother-child) relation, psychiatry, psychoanalysis, Irene Chatoor

Versão inicial recebida em abril de 2001

Aprovado para publicação em dezembro de 2001 